\title{
Zwitterionic Stealth Dye-Loaded Polymer Nanoparticles for Intracellular Imaging
}

Anne Runser, Denis Dujardin, Pauline Ernst, Andrey S. Klymchenko, * Andreas Reisch*

Laboratoire de Bioimagerie et Pathologies, CNRS UMR 7021, Université de Strasbourg, Faculté de Pharmacie, 67401 Illkirch Cedex, France.

E-mail: reisch@unista.fr; andrey.klymchenko@unista.fr 


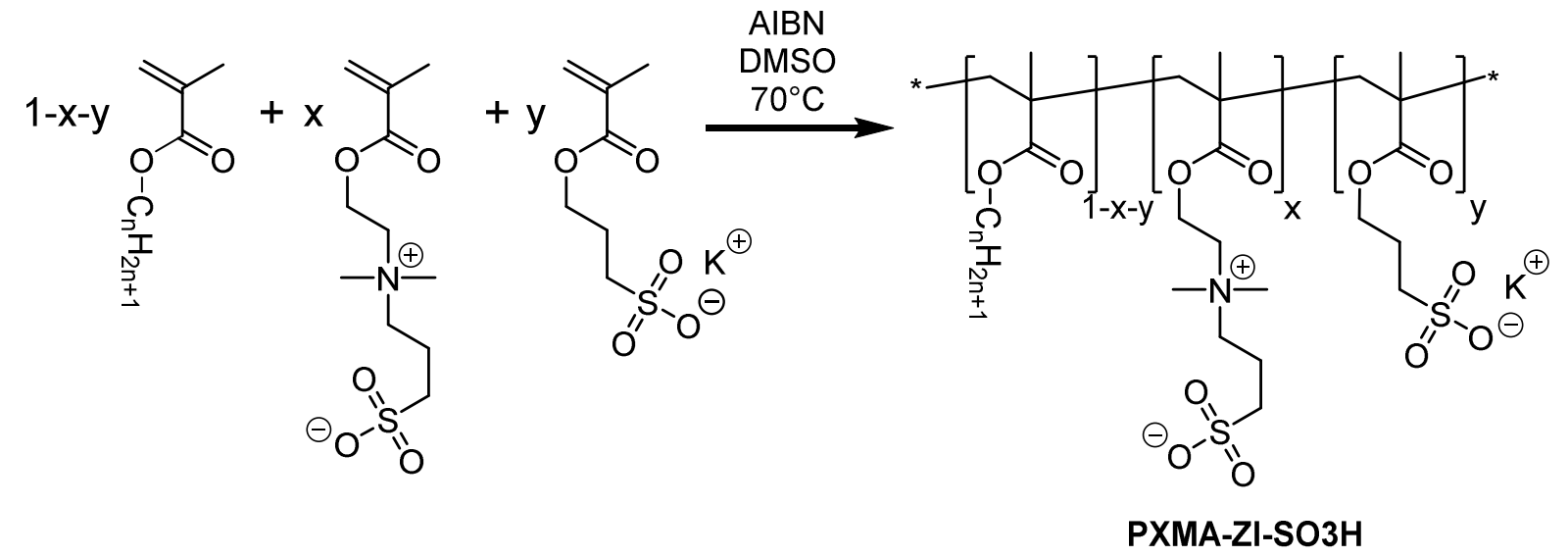

Scheme S1. Polymerization of alkyl methacrylate, ZI and sulfonate monomers to obtain methacrylate polymers bearing zwitterionic and charged groups.

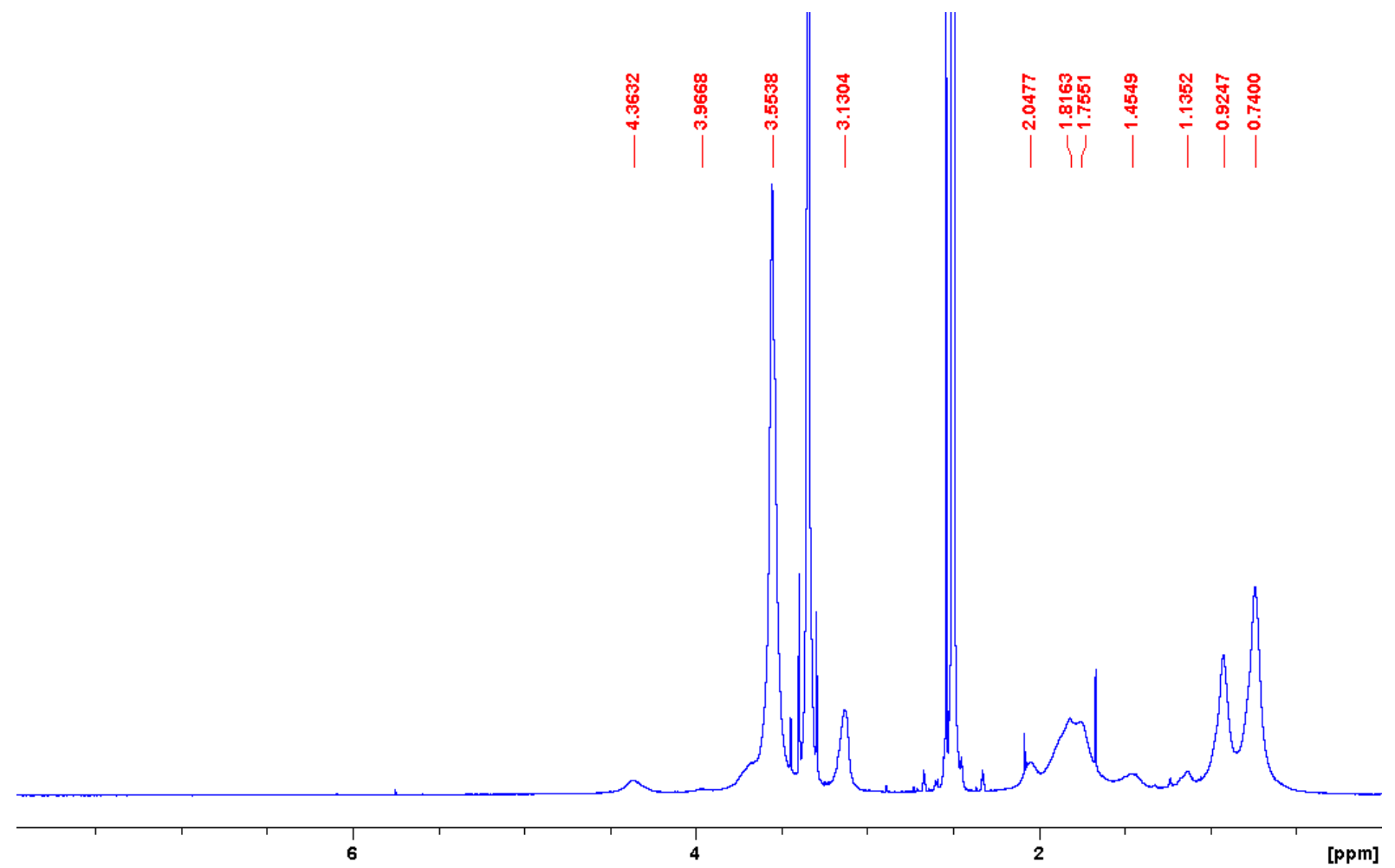

Figure S1. ${ }^{1} \mathrm{H}-\mathrm{NMR}$ spectrum of PMMA-ZI-10\%-SO $3 \mathrm{H}-1 \%$ in DMSO-d 6 . 
Table S1. Sizes of NPs made of different polymers as obtained from TEM, DLS, and FCS. ${ }^{a}$

\begin{tabular}{|c|c|c|c|c|c|}
\hline \multicolumn{2}{|c|}{ Polymer } & \multicolumn{3}{c|}{ Size (nm) } \\
\hline Main monomer & $\mathrm{SO}_{3} \mathrm{H}(\mathrm{mol} \%)$ & $\mathrm{ZI} \mathrm{(mol \% )}$ & TEM $^{\mathrm{b}}$ & $\mathrm{DLS}^{\mathrm{b}}$ & FCS $^{\mathrm{c}}$ \\
\hline MMA & 1 & - & $13 \pm 3$ & - & $14 \pm 1$ \\
\hline MMA & 1 & 10 & $11 \pm 3$ & $11 \pm 1$ & $15 \pm 1$ \\
\hline MMA & 2 & - & $9 \pm 3$ & - & $14 \pm 1$ \\
\hline MMA & 2 & 10 & $9 \pm 2$ & - & $13 \pm 1$ \\
\hline EMA & 1 & 10 & $14 \pm 3$ & $10 \pm 1$ & $11 \pm 1$ \\
\hline PMA & 1 & 10 & $22 \pm 4$ & $19 \pm 2$ & $13 \pm 1$ \\
\hline BMA & 1 & 10 & $35 \pm 7$ & $31 \pm 2$ & $32 \pm 4$ \\
\hline
\end{tabular}

${ }^{a}$ Errors correspond to width of the distribution at half maximum (FWHM) for TEM, and standard error of the mean (s.e.m.) over 3 measurements for DLS and FCS. ${ }^{b}$ NPs prepared with $10 \mathrm{wt} \%$ R18/F5-TPB. ${ }^{\mathrm{c}}$ NPs prepared with $1 \mathrm{wt} \%$ R18/F5-TPB.

Table S2. Sizes of PMMA-ZI-10\%-SO $3 \mathrm{H}-1 \%$ NPs at different $\mathrm{pH}$ values as measured by DLS. ${ }^{\mathrm{a}}$

\begin{tabular}{|c|c|}
\hline $\mathrm{pH}^{\mathrm{b}}$ & Mean size $(\mathrm{nm})$ \\
\hline 3.6 & $14 \pm 1$ \\
\hline 5.0 & $15 \pm 1$ \\
\hline 7.4 & $14 \pm 1$ \\
\hline 9.0 & $15 \pm 2$ \\
\hline
\end{tabular}

${ }^{\mathrm{a}}$ NPs were loaded with $10 \mathrm{wt} \%$ of R18/F5-TPB. ${ }^{\mathrm{b}}$ For adjusting the $\mathrm{pH}$ we used the following buffer solutions: acetate buffer for $\mathrm{pH} 3.6$ and 5; phosphate buffer for $\mathrm{pH} 7.4$; borate buffer for $\mathrm{pH}$ 9; all at $5 \mathrm{mM}$.

Table S3. Zeta potential of dye-loaded NPs made from different polymers.

\begin{tabular}{|c|c|}
\hline polymer & Zeta potential $(\mathrm{mV})$ \\
\hline PMMA-SO 3 H-1\% & -24 \\
\hline PMMA-ZI-10\%-SO ${ }_{3} \mathrm{H}-1 \%$ & -21 \\
\hline PEMA-ZI-10\%-SO $3 \mathrm{H}-1 \%$ & -28 \\
\hline PPMA-ZI-10\%-SO ${ }_{3} \mathrm{H}-1 \%$ & -34 \\
\hline
\end{tabular}


Table S4. FCS results: concentration, diameter and brightness obtained for the different zwitterionic NP solutions before and 5 min after addition of $10 \%$ fetal bovine serum (FBS). ${ }^{\mathrm{a}}$

\begin{tabular}{|c|c|c|c|c|c|}
\hline & ZI \% & $\begin{array}{l}\text { FBS addition } \\
\quad(\mathrm{vol} \%)\end{array}$ & $\begin{array}{l}\text { Concentration } \\
(\mathrm{nM})\end{array}$ & Diameter (nm) & $\begin{array}{c}\text { Brightness } \\
\text { relative to TMR }\end{array}$ \\
\hline \multirow{8}{*}{ 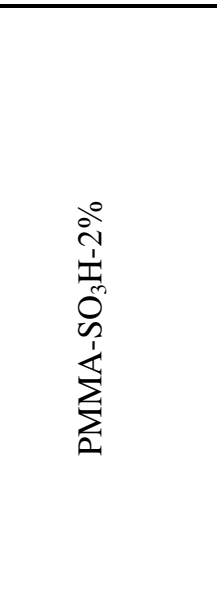 } & \multirow{2}{*}{0} & - & 18.6 & 14.1 & 5.0 \\
\hline & & 10 & 14.7 & 22.6 & 4.3 \\
\hline & \multirow{2}{*}{2} & - & 12.9 & 15.2 & 5.5 \\
\hline & & 10 & 12.2 & 24.6 & 4.4 \\
\hline & \multirow{2}{*}{5} & - & 30.7 & 8.0 & 2.7 \\
\hline & & 10 & 23.3 & 12.4 & 2.5 \\
\hline & \multirow{2}{*}{10} & - & 26.1 & 13.2 & 3.1 \\
\hline & & 10 & 20.2 & 14.6 & 2.9 \\
\hline \multirow{4}{*}{ 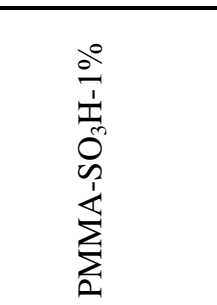 } & \multirow{2}{*}{0} & - & 17.9 & 14.0 & 6.0 \\
\hline & & 10 & 10.8 & 23.5 & 5.9 \\
\hline & \multirow{2}{*}{10} & - & 14.8 & 14.9 & 5.3 \\
\hline & & 10 & 14.5 & 15.4 & 4.6 \\
\hline \multirow{2}{*}{$\begin{array}{c}\text { PEMA-SO }{ }_{3} \mathrm{H}- \\
1 \%\end{array}$} & \multirow{2}{*}{10} & - & 34.5 & 11.0 & 2.0 \\
\hline & & 10 & 26.4 & 14.3 & 2.4 \\
\hline \multirow{2}{*}{$\begin{array}{c}\text { PPMA-SO }{ }_{3} \mathrm{H}- \\
1 \%\end{array}$} & \multirow{2}{*}{10} & - & 9.6 & 12.5 & 5.8 \\
\hline & & 10 & 7.8 & 15.9 & 5.7 \\
\hline \multirow{2}{*}{$\begin{array}{c}\text { PBMA-SO }{ }_{3} \mathrm{H}- \\
1 \%\end{array}$} & \multirow{2}{*}{10} & - & 4.2 & 31.8 & 22.1 \\
\hline & & 10 & 1.6 & 45.5 & 26.4 \\
\hline
\end{tabular}

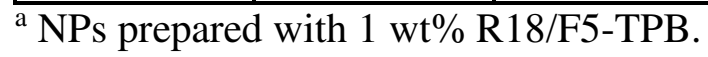



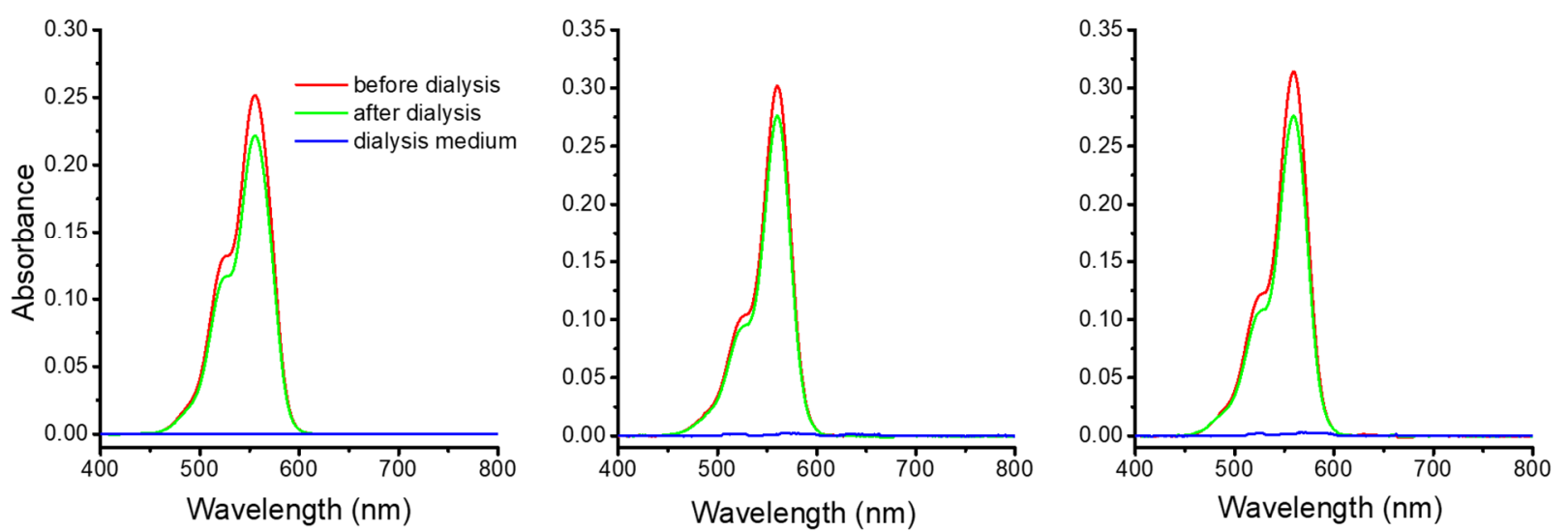

Figure S2. Absorbance spectra measured for solutions of PXMA-ZI- $10 \%-\mathrm{SO}_{3} \mathrm{H}-1$ or $2 \%$ NPs loaded with $10 \mathrm{wt} \%$ of R18/F5-TPB before (red) and after (green) dialysis for $24 \mathrm{~h}$. The blue curve corresponds to the dialysis medium after dialysis.

Table S5. Release of dye from NPs made from different polymers over 24 h. $^{\text {a }}$

\begin{tabular}{|c|c|}
\hline polymer & loss of R18/F5-TPB ${ }^{b}$ \\
\hline PMMA-ZI-10\%-SO 3 H-2\% & $14 \%$ \\
\hline PEMA-ZI-10\%-SO 3 H-1\% & $9 \%$ \\
\hline PPMA-ZI-10\%-SO ${ }_{3} \mathrm{H}-1 \%$ & $12 \%$ \\
\hline
\end{tabular}

${ }^{\mathrm{a}}$ Release was tested by dialysis for $24 \mathrm{~h}$ against a $1 \mathrm{mM}$ solution of $\beta$-cyclodextrin. Absorbance spectra were recorded for the NP solution before and for the NP solution and the dialysis solution after dialysis (Figure S5). ${ }^{\mathrm{b}}$ Relative to amount of R18/F5-TPB before dialysis. 

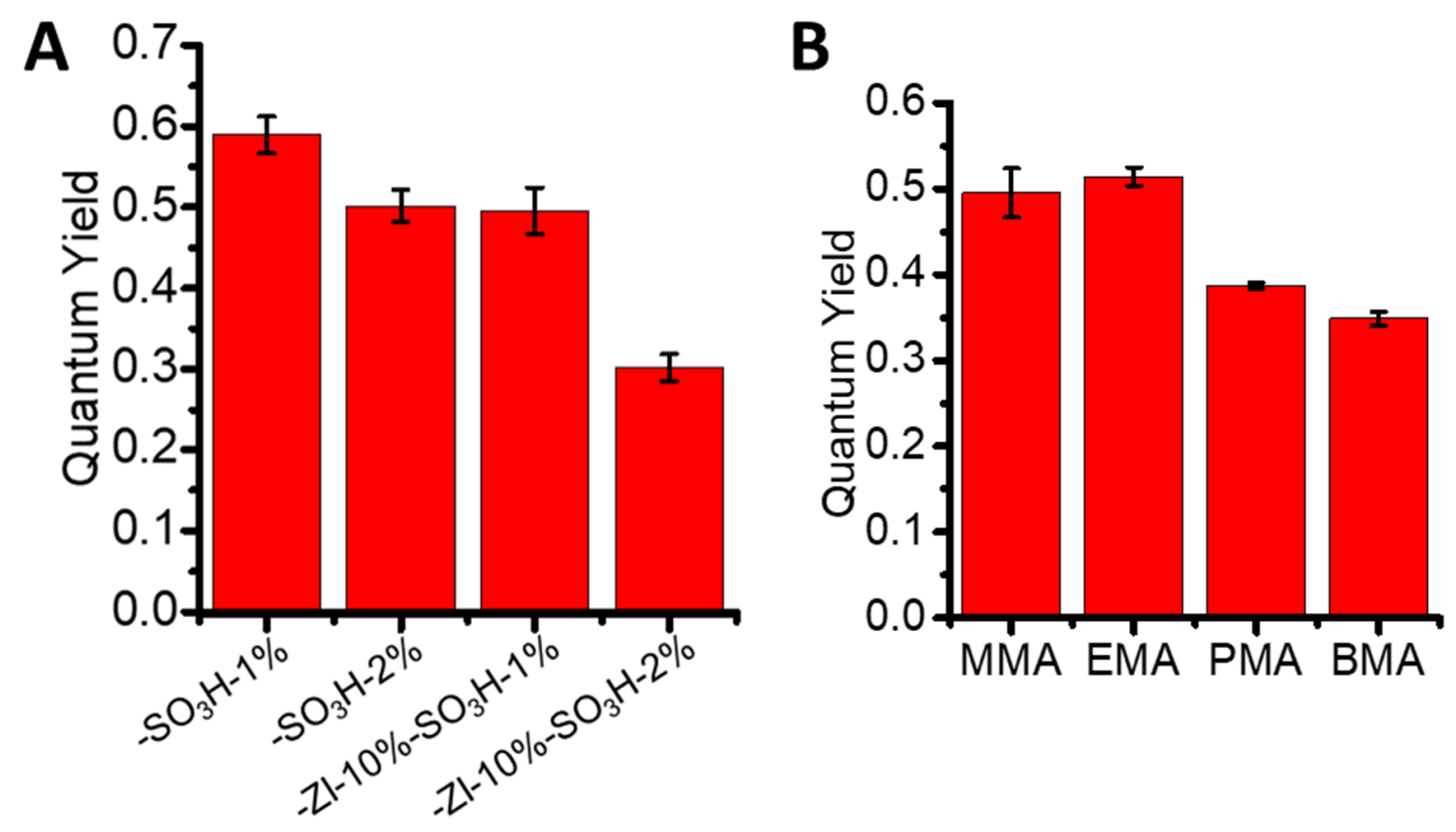

Figure S3. Quantum yield of dye-loaded NPs. NPs were made from (A) PMMA-SO $3 \mathrm{H}-1 \%$ and $2 \%$, PMMA-ZI- $10 \%-\mathrm{SO}_{3} \mathrm{H}-1 \%$ and $2 \%$ and (B) from PXMA-ZI-10\%-SO 3 H- $1 \%$ with different hydrophobic monomers. They were loaded with $10 \mathrm{wt} \%$ R18/F5-TPB. Given are mean values from three independent measurements. The error bars correspond to SEM.
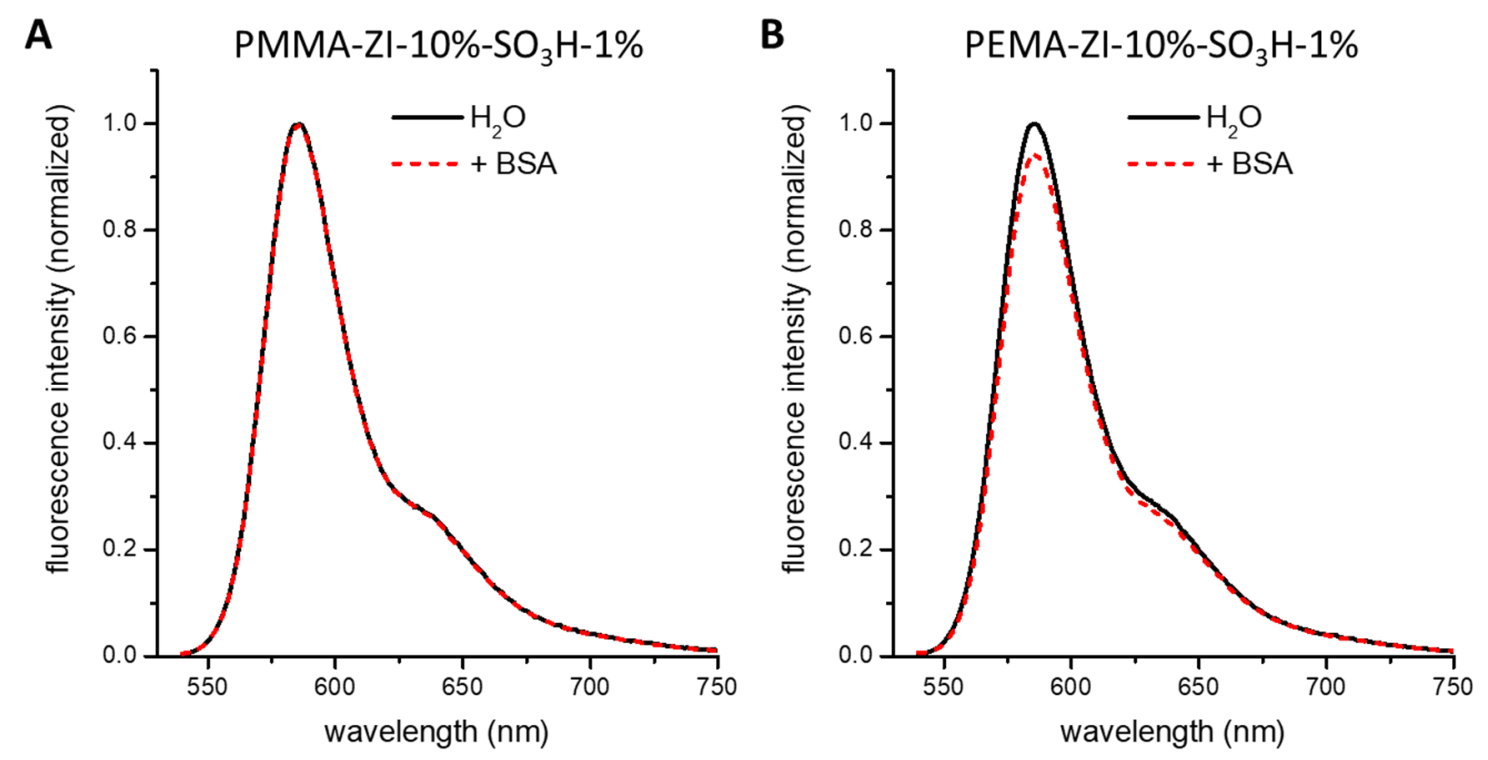

Figure S4. Fluorescence spectra of (A) PMMA-ZI-10\%-SO $3 \mathrm{H}-1 \%$ and (B) PEMA-ZI-10\%$\mathrm{SO}_{3} \mathrm{H}-1 \%$ NPs loaded with $10 \mathrm{wt} \% \mathrm{R} 18 / \mathrm{F} 5-\mathrm{TPB}$ in water and in the presence of $1 \mathrm{mg} / \mathrm{mL}$ bovine serum albumin (BSA). 
Table S6. Per particle fluorescence brightness for different zwitterionic NPs loaded with 10 wt $\%$ R18/F5-TPB. ${ }^{\mathrm{a}}$

\begin{tabular}{|c|c|c|c|c|c|}
\hline $\begin{array}{c}\text { Main } \\
\text { monomer }\end{array}$ & $\begin{array}{c}\mathrm{SO}_{3} \mathrm{H}, \\
(\mathrm{mol} \%)\end{array}$ & $\begin{array}{c}\mathrm{ZI} \\
(\mathrm{mol} \%)\end{array}$ & $\begin{array}{c}\text { TEM } \\
(\mathrm{nm})\end{array}$ & $\begin{array}{c}\text { QY } \\
\left(\mathrm{M}^{-1} \mathrm{~L}^{-1}\right)\end{array}$ \\
\hline MMA & 1 & 0 & $13 \pm 3$ & $0.58 \pm 0.04$ & $4.2 \times 10^{6}$ \\
\hline MMA & 1 & 10 & $11 \pm 3$ & $0.50 \pm 0.02$ & $2.2 \times 10^{6}$ \\
\hline MMA & 2 & 0 & $9 \pm 3$ & $0.50 \pm 0.03$ & $1.2 \times 10^{6}$ \\
\hline MMA & 2 & 10 & $9 \pm 2$ & $0.31 \pm 0.03$ & $0.9 \times 10^{6}$ \\
\hline EMA & 1 & 10 & $14 \pm 3$ & $0.51 \pm 0.04$ & $4.6 \times 10^{6}$ \\
\hline PMA & 1 & 10 & $22 \pm 4$ & $0.39 \pm 0.03$ & $1.4 \times 10^{6}$ \\
\hline BMA & 1 & 10 & $35 \pm 7$ & $0.35 \pm 0.04$ & $4.9 \times 10^{7}$ \\
\hline
\end{tabular}

${ }^{a}$ Brightness was calculated as: Brightness $=\mathrm{N}^{*} \varepsilon_{\mathrm{R} 18} * \mathrm{QY}$, where $\mathrm{N}$ is the number of fluorophores based on the loading and the NP size, $\varepsilon_{\mathrm{R} 18}$ is the absorbance of R18 at $565 \mathrm{~nm}\left(125000 \mathrm{M}^{-1} \mathrm{~L}^{-}\right.$ ${ }^{1}$ ) and QY is the measured quantum yield. 


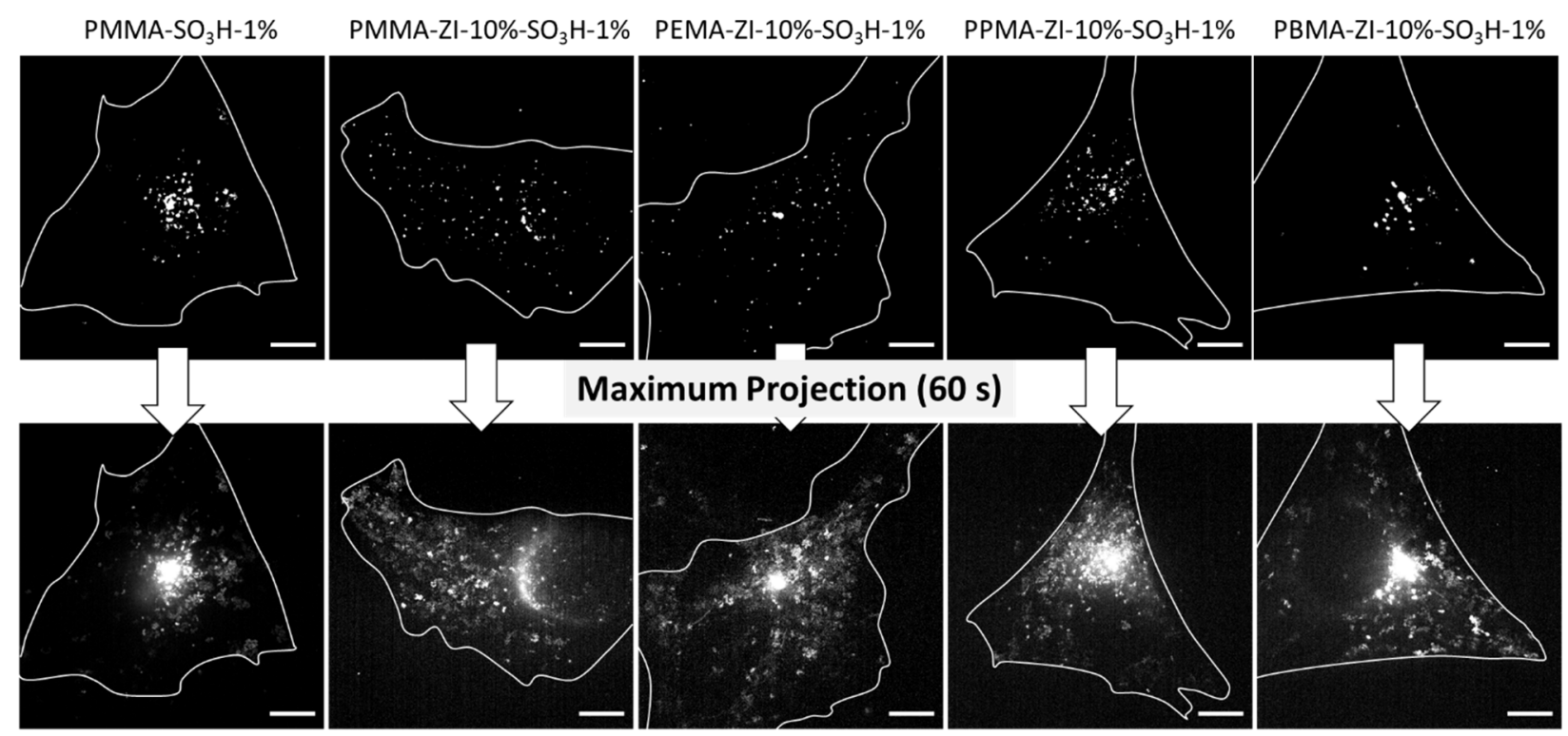

Figure S5. Approximate outline of cells obtained from phase-contrast images marked on representative epi-fluorescence micrographs of HeLa cells microinjected with different types of NPs loaded with $10 \mathrm{wt} \%$ R18/F5-TPB. Top: single frame (50 ms exposure); bottom: maximum projections over $60 \mathrm{~s}$. Scale bars correspond to $10 \mu \mathrm{m}$.

Table S7. Percentage of fluorescence at the injection point to total NP fluorescence in cells microinjected with different types of NPs loaded with 10 wt\% R18/F5-TPB.

\begin{tabular}{|c|c|}
\hline polymer & Fluorescence at the injection point $(\%)^{\mathrm{a}}$ \\
\hline PMMA-SO 3 H- $1 \%$ & $39 \pm 10$ \\
\hline PMMA-ZI-10\%-SO ${ }_{3} \mathrm{H}-1 \%$ & $6 \pm 2$ \\
\hline PEMA-ZI-10\%-SO ${ }_{3} \mathrm{H}-1 \%$ & $10 \pm 1$ \\
\hline PPMA-ZI-10\%-SO ${ }_{3} \mathrm{H}-1 \%$ & $7 \pm 2$ \\
\hline PBMA-ZI-10\%-SO $3 \mathrm{H}-1 \%$ & $35 \pm 12$ \\
\hline
\end{tabular}

${ }^{a}$ The fluorescence in the entire cell and the fluorescence in a circle of about $5 \mu \mathrm{m}$ around the injection point were measured for at least 3 different fields of view per condition. Given is the ratio of fluorescence at the injection point to the total fluorescence in the NP channel in the cell. 

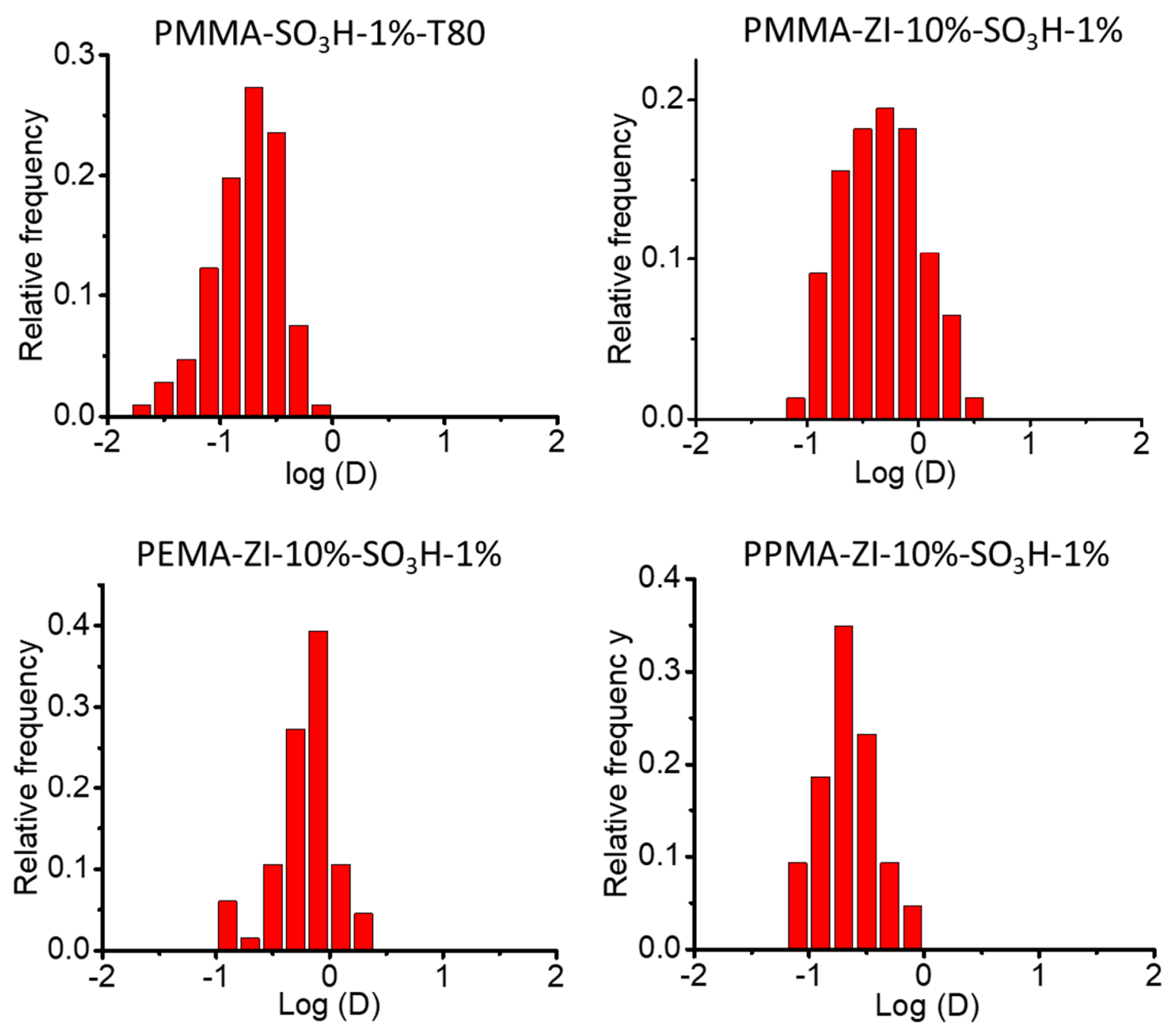

Figure S6. Distribution of diffusion coefficients $\left(\mu \mathrm{m}^{2} \cdot \mathrm{s}^{-1}\right)$ of NPs in the cytosol obtained from MSD curves. 